\title{
I22. VITAMIN METHODS
}

\section{A NOTE ON VITAMIN $B_{1}$ IN URINE AS DETERMINED CHEMICALLY AND -BIOLOGICALLY}

\author{
By LESLIE J. HARRIS AND Y. L. WANG \\ From the Dunn Nutritional Laboratory, University of Cambridge \\ and Medical Research Council
}

(Received 31 July 1941)

WANG \& HARRIS [1939] described a method for estimating vitamin $\mathrm{B}_{1}$ in urine by a modification of the thiochrome reaction and found that their results agreed well with those determined biologically. Hills [1939] claims to have improved the procedure; yet states that the results by his method are $30 \%$ lower on the average than those determined by him according to our method. This apparent discrepancy has prompted us to carry out yet another series of biological comparisons on urine. The new determinations increase our confidence in the reliability of our method.

Two urines from normal subjects have been tested, one having a relatively high and the other a low content of vitamin $B_{1}$. For the biological determination it was necessary to adsorb the vitamin before dosing. For this purpose the urines were diluted 3-4 times with water, adjusted to $p \mathrm{H} 4$ and treated with 'clarit' clay, $10 \mathrm{~g}$. per $1600 \mathrm{ml}$. of diluted urine. The urines were analysed by the thiochrome method before and after adsorption, the percentage of the vitamin adsorbed being found by difference. In one instance $86 \%$ was shown to be adsorbed and in the other $82 \%$. In the biological tests the adsorbates were administered to the rats directly. As the biological and chemical values both refer to the adsorbate, the small amount lost on adsorption does not enter into the comparison. Normally it would be included in the chemical test, which we carry out on the whole urine without prior adsorption [cf. however, Hills, 1939; Jowett, 1940].

The bradycardia method was used for the biological tests and the results are summarized in Table 1. To make the check as accurate as possible a fairly large number of duplicate doses were tested at each level. To equalize conditions for the rat, the solution of vitamin $B_{1}$ used as the standard was not administered as such but was first poured on to specimens of 'clarit' clay identical with those used for the urine adsorbate. The dose-response curve used for calculating the results is given in Fig. 1.

The technique for the thiochrome test was the same as that previously described.

Occasionally, especially with stale specimens, the final matching of fluorescence is found to be difficult. Sometimes, in such instances, a preliminary treatment with permanganate may help to improve the end point by removing the blank fluorescence without significant destruction of the vitamin $B_{1}$. This procedure can only be used with safety, however, with urines which are not too strongly reducing, otherwise appreciable destruction of the vitamin does occur. The working directions are as follows: before washing with water-saturated isobutanol, add 2 drops of conc. $\mathrm{H}_{2} \mathrm{SO}_{4}$ to $5 \mathrm{ml}$. of the urine. Then add a $1 \%$ solution of $\mathrm{KMnO}_{4}$ drop by drop with continual stirring, allowing complete decoloration before the next drop is added. Discontinue the addition when a faint pink colour appears which persists for about 1 min. Add one drop of $0.5 \% \mathrm{H}_{2} \mathrm{O}_{2}$ solution and continue as in the usual procedure. 
Table 1. Biological tests

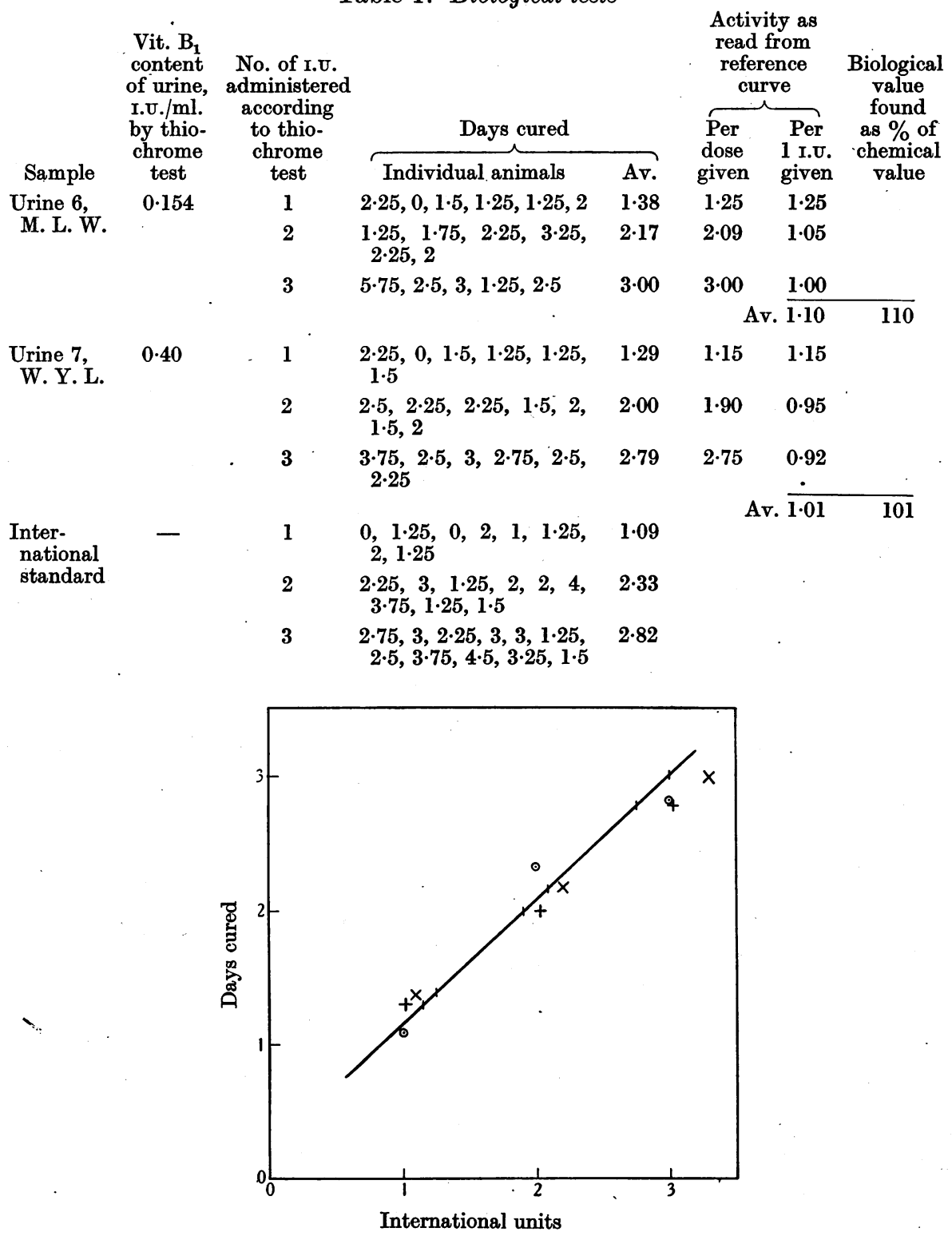

Fig. 1. Dose-response curve. $\odot=$ Standard. $\quad x=$ Urine No. $6 . \quad+=$ Urine No. 7 .

Agreement between the chemical and biological findings (Table 1) seems very good. For one urine the biological value is $110 \%$ of the chemical and for the other it is $101 \%$. In the earlier tests [Wang \& Harris, 1939], on 5 specimens of urine, the biological values were $100,121,100,89$ and $128 \%$ of the chemical values, making an average of $108 \%$, or an average of $107 \%$ for all 7 specimens in the two investigations. 
That slightly lower results are given by the thiochrome test than by the biological test accords with our general experience of other animal and plant. materials and of foodstuffs [Harris \& Wang, 1941]. Methods like those of Hills which give still lower chemical results may therefore be expected to be all the more in error-viz. to the extent of more than $30 \%$, to judge from the differences between the results given by the two methods as published by Hills.

Jowett, who criticized the uncertainties in the method of Hills, diminished the error by substituting synthetic zeolite for activated earth. But even with this improvement, various possible sources of error remain-including incomplete adsorption and elution-and as Jowett himself concedes, his procedure, although convenient and simple, will not estimate low excretions accurately.

As an additional check we have carried out further recovery tests in which known amounts of vitamin $B_{1}$ were added to urine. The recovery has always been virtually complete (Table 2 ).

Table 2. Recovery of vitamin $B_{1}$ added to normal urines

\begin{tabular}{|c|c|c|c|c|}
\hline Sppecimen & $\begin{array}{c}\text { Vitamin } B_{1} \\
\text { present } \\
\mu \mathrm{g} . \text { per ml. }\end{array}$ & $\begin{array}{c}\text { Additional } \\
\text { vitamin } \mathrm{B}_{1} \\
\text { added } \\
\mu \mathrm{g} . \text { per ml. }\end{array}$ & $\begin{array}{c}\text { Additional } \\
\text { vitamin } B_{1} \\
\text { found } \\
\mu \mathrm{g} . \text { per } \mathrm{ml} \text {. }\end{array}$ & $\begin{array}{c}\text { Recovery } \\
\%\end{array}$ \\
\hline Urine 1 & $\begin{array}{l}0 \cdot 118 \\
0 \cdot 118\end{array}$ & $\begin{array}{l}0 \cdot 16 \\
0 \cdot 16\end{array}$ & $\begin{array}{l}0 \cdot 15 \\
0 \cdot 15\end{array}$ & $\begin{array}{l}94 \\
94\end{array}$ \\
\hline Urine 2 & 0.472 & $0 \cdot 32$ & $0 \cdot 36$ & 112 \\
\hline Urine 3 & $\begin{array}{l}0.378 \\
0.408\end{array}$ & $\begin{array}{l}0 \cdot 32 \\
0 \cdot 32\end{array}$ & $\begin{array}{l}0 \cdot 31 \\
0 \cdot 287\end{array}$ & $\begin{array}{l}97 \\
90\end{array}$ \\
\hline Urine 4 & 0.0812 & $0 \cdot 32$ & $0 \cdot 291$ & 91 \\
\hline
\end{tabular}

Since this note was written, a study by Slater [1941] has also appeared. His findings accord excellently with our own. He concludes: 'the thiochrome method of Wang \& Harris can be satisfactorily applied to the determination of thiamin in milk and cereal products [and urine].... Criticisms by Hills [1939] of the Wang \& Harris method of determining thiamin in urine appear to be unjustified... The recovery of added thiamin is quantitative in all cases.'

\section{SUMMARY}

A further comparison has been made of the results obtained by the improved thiochrome method of Wang \& Harris with those obtained by biological tests (bradycardia method). The agreement is good. On one specimen of urine the biological value was $110 \%$ of the chemical and on another $101 \%$; in earlier tests the values were $100,121,100,89,128 \%$; average for both series is $107 \%$. Recovery tests confirm the reliability of the method.

\section{REFERENCES}

Harris \& Wang (1941). Biochem. J. 35, 1050.

Hills (1939). Biochem. J. 33, 1966.

Jowett (1940). Biochem. J. 34, 1348.

Slater (1941). Aust. J. exp. Biol. med. Sci. 19, 29.

Wang \& Harris (1939). Biochem. J. 33, 1356. 